\title{
Acessibilidade em instituição de ensino superior no Tocantins: relato de caso
}

\author{
Accessibility in a higher education institution in Tocantins: case report \\ Accesibilidad en una institución de educación superior en Tocantins: reporte de caso
}

Recebido: 02/10/2021 | Revisado: 09/10/2021 | Aceito: 14/10/2021 | Publicado: 17/10/2021

\author{
Gabriela Fachine Brito \\ ORCID: https://orcid.org/0000-0002-9879-2899 \\ Universidade Federal do Tocantins, Brasil \\ E-mail: gabrielafachine@gmail.com \\ Eskálath Morganna Silva Ferreira \\ ORCID: https://orcid.org/0000-0002-2298-3656 \\ Universidade Federal do Tocantins, Brasil \\ E-mail: morganna_ferreira@hotmail.com
}

\begin{abstract}
Resumo
O presente artigo teve como objetivo verificar o processo de inclusão de uma Instituição de Ensino Superior (IES) do Tocantins. Inicialmente, elaborou-se um breve contexto sobre educação inclusiva, pois esta ideia surgiu pela necessidade de conhecer o que está sendo realizado na área de educação especial em uma instituição de ensino superior do Tocantins. Posteriormente, foi realizada uma pesquisa com enfoque qualitativo, com os discentes e com os colaboradores da IES que trabalham diretamente com estes discentes, e a partir dos dados que foram coletados, foi possível mensurar a qualidade dos serviços oferecidos pela IES, que atualmente possui 42 acadêmicos com necessidades educacionais especiais. Vale ressaltar que a IES utilizada na pesquisa é uma das maiores instituições do Estado, contando aproximadamente com 6 mil discentes. Por fim, foram sugeridas melhorias de adaptações e possíveis potencialidades para serem alcançadas pelos acadêmicos especiais e, todos os envolvidos no processo de ensino-aprendizagem da IES. A IES utilizada neste relato fornece subsídios necessários para viabilizar o processo de inclusão.
\end{abstract}

Palavras-chave: Inclusão; Ensino superior; Acessibilidade; Ensino-aprendizagem.

\begin{abstract}
This article aimed to verify the inclusion process of a Higher Education Institution (HEI) in Tocantins. Initially, a brief context on inclusive education was elaborated, as this idea arose from the need to know what is being done in the area of special education in a higher education institution in Tocantins. Subsequently, a survey with a qualitative focus was carried out with the students and employees of the IES who work directly with these students, and from the data that were collected, it was possible to measure the quality of services offered by the IES, which currently has 42 academics with special educational needs. It is noteworthy that the HEI used in the research is one of the largest institutions in the state, with approximately 6 thousand students. Finally, improvements were suggested for adaptations and possible potential to be achieved by special academics and all those involved in the teaching-learning process at the IES. The HEI used in this report provides the necessary subsidies to make the inclusion process viable.
\end{abstract}

Keywords: Inclusion; Higher education; Accessibility; Teaching-learning.

\section{Resumen}

Este artículo tuvo como objetivo verificar el proceso de inclusión de una Institución de Educación Superior (IES) en Tocantins. Inicialmente se elaboró un breve contexto sobre educación inclusiva, ya que esta idea surgió de la necesidad de conocer qué se está haciendo en el área de educación especial en una institución de educación superior en Tocantins. Posteriormente, se realizó una encuesta con un enfoque cualitativo a los estudiantes y empleados de las IES que trabajan directamente con estos estudiantes, y a partir de los datos que se recolectaron, se pudo medir la calidad de los servicios que ofrecen las IES, que actualmente tiene 42 académicos con necesidades educativas especiales. Cabe mencionar que la IES utilizada en la investigación es una de las instituciones más grandes del estado, con aproximadamente 6 mil estudiantes. Finalmente, se sugirieron mejoras para las adaptaciones y posibles potencialidades a ser alcanzadas por académicos especiales y todos los involucrados en el proceso de enseñanzaaprendizaje en el IES. La IES utilizada en este informe proporciona los subsidios necesarios para viabilizar el proceso de inclusión.

Palabras clave: Inclusión; Educación superior; Accesibilidad; Enseñanza-aprendizaje. 


\section{Introdução}

A plena participação social das pessoas com deficiência é fundamental e envolve o acesso a uma educação de qualidade e ao mercado de trabalho. A viabilização para este acesso começa na escola e se consolida, sobretudo, no ensino profissionalizante, sendo de suma importância o papel de uma educação produtiva para a aplicação de fato do que é imposto nas políticas inclusionistas (Silva et al., 2012).

No Brasil, desde a implantação da Constituição Federal (1988) foi estabelecido que a educação é direito de todos. A educação especial deve ser oferecida aos alunos desde a educação infantil até a educação superior e tem como objetivo assegurar a inclusão escolar desses alunos, orientando os sistemas de ensino para garantir, dentre outros aspectos, a acessibilidade arquitetônica desde os transportes, nas instalações e equipamentos, nas comunicações e no transpasse de informações (Guerreiro, 2012).

O ingresso do aluno com deficiência é um avanço no ensino superior, porém é necessário observar que não só pelo fato de o aluno ter sido matriculado e estar na sala de aula não significa, necessariamente, que ele esteja tendo um conhecimento produtivo e absorvendo os conteúdos propostos. Para tanto, é necessário que as instituições de ensino superior realizem adequações para que a inclusão seja de fato efetiva, tendo um mapeamento desde o ingresso e acompanhamento deste aluno durante toda a sua permanência, oferecendo serviços de apoio, tornando-se assim um processo de inclusão (Moreira et al., 2011).

A questão da acessibilidade é fundamental, pois sem ela a pessoa é privada de usufruir dos demais direitos fundamentais que lhe são conferidos como cidadão, tais como direito a educação, a saúde, ao trabalho, ao lazer e outros. A acessibilidade funciona como instrumento para utilização desses outros direitos (Leite, 2007). Acessibilidade é a possibilidade de qualquer pessoa, independentemente de suas capacidades físico-motoras, cognitivas, culturais e sociais, usufruir os benefícios de uma vida em sociedade, ou seja, é a possibilidade de participar de todas as atividades, até as que incluem o uso de produtos, serviços e informação, com o mínimo de restrições possível (Nicholl, 2001).

No contexto de educação acessível, principalmente quando se refere ao ensino superior, existe um certo distanciamento ao acesso a esse nível de ensino, por parte dos alunos com necessidades educacionais especiais. Além de serem poucos os alunos que conseguem ingressar nessa modalidade de ensino, estes ainda enfrentam diversas dificuldades em sua jornada acadêmica, apresentando desta forma, a realidade do ensino brasileiro (Simionato, 2011).

Com relação a educação, a acessibilidade é considerada a condição para utilização, com segurança e autonomia, total ou assistida, dos dispositivos e dos sistemas e meios de comunicação e informação. Sendo as barreiras consideradas como qualquer entrave ou obstáculo que limite ou impeça o acesso e a possibilidade das pessoas de se comunicarem ou terem acesso à informação (BRASIL, 2004). Essa inadequação, segundo Malheiro (2018) pode impedir a plena e efetiva participação, em igualdade de oportunidades, com os demais estudantes no ambiente acadêmico, presencial ou virtual.

Diante desta realidade, o presente artigo visa contribuir para tal discussão e para tanto, estabeleceu como objetivo fazer um levantamento, através de questionários, sobre a opinião dos alunos que possuem alguma necessidade educacional especializada e/ou locomotora e dos professores e colaboradores de uma Instituição de Ensino Superior (IES) do estado do Tocantins que lidam diretamente com estes alunos. Além disso serão discutidos os resultados encontrados a partir desse levantamento realizado com os envolvidos no processo de ensino-aprendizagem.

\subsection{Breve perfil da IES utilizada na pesquisa}

A IES iniciou suas atividades no Tocantins na década de 90 oferecendo educação básica, ensino fundamental, ensino médio e educação superior para alguns cursos. Atualmente conta com 22 cursos de graduação presencial, 19 cursos de pósgraduação presencial e 21 cursos de pós-graduação à distância. Um diferencial da IES é a inclusão de alunos com de 
necessidades especiais, pois eles possuem um Núcleo de Atendimento Educacional Especializado (NAEE) direcionado aos alunos com algum tipo de deficiência, seja ela física, mental, cognitiva, visual e/ou auditiva. O NAEE foi fundado em 2011 dentro da IES com o objetivo de realizar o auxílio de alunos com necessidades especiais e realizar atendimentos psicológicos aos discentes.

O NAEE possui psicólogos, pedagogos, intérpretes de libras e corpo administrativo. A demanda atual da IES conta com 1 aluno surdo, 2 alunos cegos, 3 alunos cadeirantes, 5 alunos baixa visão, 2 alunos com deficiência mental, 1 aluna com dificuldade locomotora e cerca de 30 alunos com deficiência cognitiva (dislexia, discalculia, déficit de atenção, hiperatividade, entre outros). O trabalho exercido pelo NAEE envolve 3 eixos: saúde mental, onde são realizados atendimentos psicológicos com os discentes que necessitam deste tipo de serviço; ensino-aprendizagem, onde são ensinadas técnicas de estudo; e, acessibilidade, onde é envolvida a questão de tradução das aulas em libras para alunos surdos, ampliação de materiais para alunos baixa visão, aplicação de provas para alunos com deficiências cognitivas em local mais apropriado e individualizado.

O trabalho do intérprete de libras é acompanhar o aluno surdo em todas as aulas, realizando a tradução do que é ensinado pelo professor para libras/português e vice-versa. Vale ressaltar que no NAEE os alunos com necessidades especiais fazem provas no próprio setor, com o acompanhamento dos colaboradores do setor. Esse atendimento é especializado de acordo com a necessidade do aluno e lhe é garantido tempo adicional para a realização das provas, pois eles fornecem $50 \%$ a mais do tempo, do que é ofertado para os demais alunos.

A IES possui computadores com programas de tecnologia assistida, para auxiliar alunos cegos e baixa visão; também possui impressoras e scanners capacitados em realizar a adaptação para estes alunos; atualmente conta com duas cadeiras de rodas, para necessidades temporárias, microsystem, gravadores e fones de ouvido para alunos que necessitem deste tipo de aparelhagem. Além disso o NAEE possui alguns monitores exclusivos (monitores são alunos que passam por treinamentos para auxiliar os alunos especiais), que auxiliam alunos em sala de aula, como por exemplo, aluno cego, neste caso o monitor o acompanha em todas as aulas, realiza a leitura para ele e fornece todo o suporte necessário. Além disso, a biblioteca da IES conta com alguns livros em braille e a IES conta com pisos táteis direcionais em vários pontos, como bibliotecas, rampas, lanchonetes, corredores, salas de aulas, entre outros, de forma a facilitar a mobilidade de alunos baixa visão e cegos.

\section{Metodologia}

A pesquisa apresentada segue a abordagem qualitativa, pois esta abordagem expressa a percepção dos indivíduos envolvidos no processo (Nagai et al., 2007). A metodologia qualitativa é usada no campo de estudos das deficiências (Cheer et al., 2003; Kroll et al., 2006; Quines et al., 1985). As etapas envolvidas neste processo estão descritas na Figura 1, a seguir.

Figura 1 - Metodologia da Pesquisa.

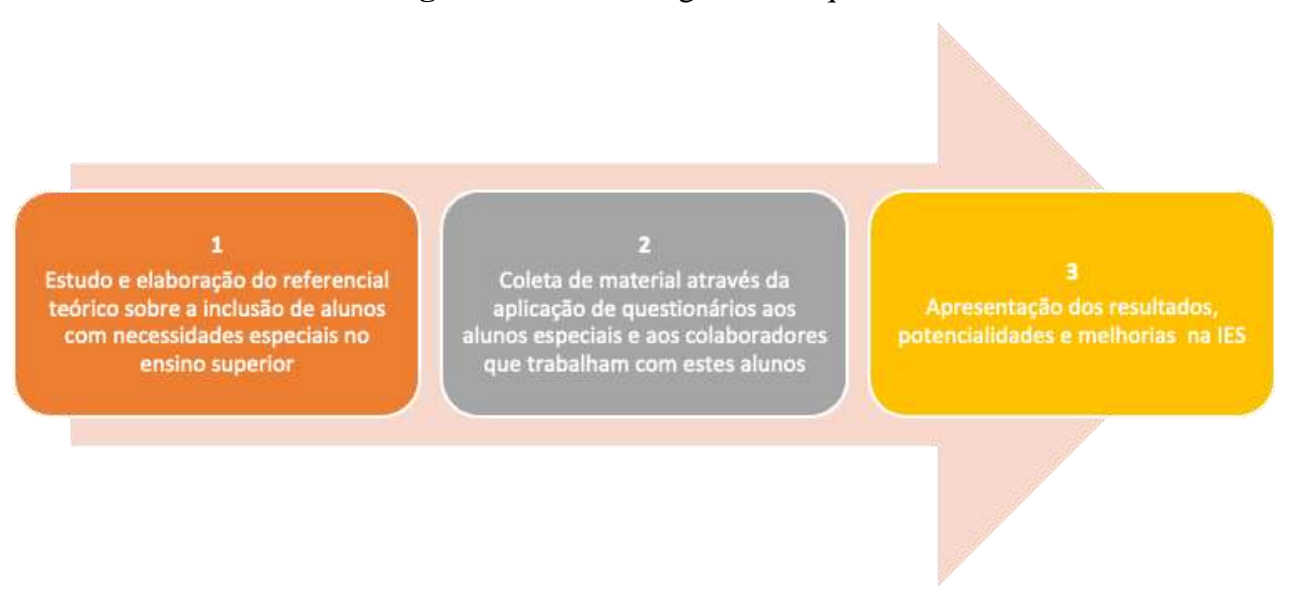

Fonte: Autores. 
Conforme apresentado na Figura 1, a metodologia da pesquisa utilizada neste artigo envolveu três etapas: na primeira etapa foi feito um estudo acerca da inclusão dos alunos especiais no ensino superior, onde foi possível observar os direitos e deveres que regem os alunos e das instituições de ensino que recebem estes alunos. A segunda etapa da pesquisa foi a elaboração de um questionário, que teve perguntas pertinentes ao acolhimento destes alunos com necessidades especiais na IES utilizada na pesquisa; ressalta-se que foram feitos dois questionários diferentes, um específico para os discentes e um específico para os colaboradores da IES. A partir da segunda etapa foi possível coletar os dados e fazer as devidas análises que serão discutidas na seção Resultados e Discussões. A terceira etapa foi realizada em conformidade com os resultados obtidos na segunda etapa, onde foram confeccionadas planilhas para facilitar o entendimento das respostas encontradas. Além disso, foram apontadas possíveis melhorias para as queixas encontradas durante a etapa dois.

O local escolhido para a realização do estudo foi uma IES do estado do Tocantins, visto que o trabalho propõe visualizar como acontece o processo de inclusão nessa modalidade de ensino. O período em que foram feitas as entrevistas variou entre o dia 5 e dia 30 de setembro de 2020. Os sujeitos da pesquisa foram os discentes especiais, que totalizaram 42 alunos entrevistados e os colaboradores que trabalham diretamente com estes alunos, sendo um total de 87 colaboradores, aos quais foram entregues questionários acerca do trabalho que vem sendo desenvolvido pela IES. Vale ressaltar que todos os alunos convidados $(n=42)$ participaram da pesquisa. Em contrapartida, foram convidados 104 colaboradores, porém apenas 87 participaram da pesquisa; a não participação foi justificada, na maioria das vezes, por falta de tempo para o encontro e consequentemente, colaboração com a pesquisa. No questionário dos discentes foram aplicadas 7 questões e no questionário dos colaboradores foram aplicadas 5 questões. Destaca-se que em um dos questionários, ao discente surdo, foi utilizado do recurso de um intérprete de libras da IES, que fez toda tradução necessária durante a pesquisa.

Após a coleta dos dados, o material foi organizado e analisado, tendo por base as respostas contidas nos questionários aplicados. Foram feitas planilhas no programa Excel, de forma a reorganizar os resultados obtidos, que serão descritos na seção seguinte, juntamente com as considerações feitas por todos os participantes da pesquisa. Destaca-se que a pesquisa foi aplicada aos colaboradores entregando o questionário para os mesmos responderem e que, para os alunos, a pesquisa foi aplicada de forma oral juntamente com uma entrevista gravada, visto que as demandas educacionais de cada um interfeririam no questionário impresso, por isso para os alunos a pesquisa foi feita de forma oral.

\section{Resultados e Discussão}

Nesta seção serão apresentados os resultados encontrados a partir dos questionários aplicados, aos quais foram divididos em duas partes: a primeira parte apresentará o resultado conforme a visão dos discentes entrevistados; e a segunda parte apresentará o resultado conforme a visão dos colaboradores entrevistados, dentre eles o corpo administrativo e os professores.

A primeira pergunta realizada aos discentes foi a respeito do ingresso dos mesmos a IES, ou seja, se a prova do vestibular esteve adequada conforme a sua necessidade especial e se o mesmo fez a solicitação de atendimento especial. Dos 42 alunos pesquisados, 13 se demonstraram satisfeitos com relação a prova do vestibular. Em contrapartida, 29 discentes se demonstraram insatisfeitos com o serviço oferecido pelo vestibular. A maior queixa apontada pelos alunos foi de fato, a falta de acessibilidade, pois a prova do vestibular foi a mesma para todos os alunos, sem particularidades como fonte da letra maior para alunos baixa visão ou prova sinalizada para alunos surdos. Um ponto positivo foi o fato destes alunos terem tido uma sala particular e com direito a intérprete de libras e monitores que os auxiliassem. Porém, este trabalho poderia ter sido evitado caso a prova fosse adaptada para cada particularidade, tornando o aluno mais independente.

A Lei no 9.394/1996 (1996), que normatiza as Diretrizes e Bases da Educação Nacional, tem um de seus capítulos dedicado à Educação Especial. Nesse capítulo fica claro que o aluno deve ter todo o suporte necessário em qualquer nível de 
ensino e o atendimento educacional deverá ser adaptado às suas necessidades específicas (BRASIL, 1996). Dessa forma, mudanças devem ser realizadas pela comissão de vestibular da IES estudada, no que se refere aos recursos adaptados para que o candidato possa realizar a prova da maneira mais livre possível. Baseado nisso, no que se refere ao acesso a este nível de ensino, o processo de ingresso destes alunos deverá se tornar cada vez mais adaptado, oferecendo garantias e podendo ser controlado pelos próprios vestibulandos (Dussilek, 2017).

A segunda pergunta realizada aos discentes foi a respeito do Núcleo de Atendimento Educacional Especializado (NAEE), se os mesmos tinham conhecimento que na IES havia este setor antes mesmo de se matricularem. Dos 42 alunos pesquisados, 34 alunos informaram que não sabiam da existência do NAEE antes de ingressar na IES. E 8 alunos informaram que já sabiam e que outros colegas já haviam indicado a IES justamente por conta do apoio oferecido.

O decreto no 6.571/08 define o atendimento educacional especializado (AEE) como um apoio a aprendizagem de alunos com necessidades educacionais especiais, englobando atividades, recursos de acessibilidade e pedagógicos, de forma a complementar a formação dos alunos no processo de ensino-aprendizagem. O AEE deve ser dotado de equipamentos, instalações, materiais didáticos e pedagógicos apropriados, de forma a eliminar barreiras e garantir a permanência do aluno na IES (BRASIL, 2008).

A pergunta número 3 questionou se os alunos utilizavam o serviço oferecido pelo NAEE, já que o setor mantém todo o histórico de alunos especiais que entram na IES todos os semestres e acompanham estes alunos até o término de suas graduações. Dos 42 alunos pesquisados, 39 informaram que sim, utilizavam dos serviços oferecidos pelo NAEE. Os 2 alunos que disseram que não utilizavam do serviço informaram que a necessidade especial deles era apenas locomotora (pois os 2 são cadeirantes), não havendo muito vínculo com o setor.

$\mathrm{O}$ acesso dos alunos com deficiência ao ensino superior levanta um questionamento a respeito das condições desse segmento de ensino, não apenas no que se refere ao ingresso, mas à permanência e ao sucesso desses alunos durante toda sua jornada acadêmica (STROPARO et al., 2016). Embora as ações de apoio na universidade estejam presentes, as mudanças necessárias para responder às demandas ainda representam inúmeros desafios.

A questão número 4 foi a respeito da satisfação do serviço prestado pelo NAEE. A questão anterior focou no uso e a questão atual se o uso é satisfatório ou não, ou seja, se atende as suas necessidades. Dos 42 alunos pesquisados, 41 se demonstraram satisfeitos com o serviço oferecido pelo NAEE, até mesmo 1 dos 2 que disseram que não utilizavam do serviço se demonstrou satisfeito, pois os funcionários do setor sempre entram em contato com os alunos no início do semestre para saber do andamento dos alunos na IES. O único aluno que informou que não estava satisfeito pelo serviço foi um aluno que informou que não utilizava o serviço e que o mesmo era indiferente para ele.

Portanto, a educação inclusiva de modo geral, que abrange o contexto universitário, pauta-se na reorganização da estrutura de como a mesma está organizada, para que atenda à realidade da população que acessa a educação nos dias atuais. Isso demonstra que um papel importante das instituições de ensino superior é lidar com o ser humano diferente e dentro dos cenários de políticas públicas de inclusão (Rosseto, 2009).

A questão de número 5 foi relacionada às leis que garantem o acesso das pessoas com necessidades especiais no ensino superior, se estes alunos tinham este conhecimento prévio acerca destas leis. Dos 42 alunos pesquisados, 36 informaram que não tinham o conhecimento das leis que lhe garantem o acesso ao ensino superior, e apenas 6 demonstraram ter este conhecimento.

A medida em que a sociedade se torna acessível e apta para o recebimento das divergências intelectuais e físicas, surgem novas demandas de estruturação e de recursos humanos; então o conceito de acessibilidade toma o contorno de promover a remoção de quaisquer barreiras que impeçam as pessoas com deficiência de participarem de qualquer atividade no ensino superior (Silva, 2016). 
A pergunta número 6 questionou se os alunos com necessidades especiais já sofreram algum tipo de discriminação dentro da IES, tanto por parte de seus professores, quanto por parte de funcionários da instituição. Dentre os 42 alunos pesquisados, 35 informaram que nunca sofreram nenhum tipo de discriminação dentro da IES, porém 7 discentes informaram que já sofreram discriminações, mais precisamente em sala de aula, advindos dos próprios docentes. A queixa principal nesta questão foi o professor não adaptar os materiais e vídeos utilizados em aulas.

Para Chahini (2010), as ações afirmativas se constituem como alternativas primordiais para que a sociedade se adapte à realidade e modifique suas atitudes, diante do acesso dessa parcela da população em níveis elevados de ensino. Assim, acolher as diferenças nos espaços de formação universitária remeterá a pensar que é preciso abandonar a educação tradicional e tentar adaptar e acolher possíveis divergências educacionais encontradas durante o caminho de ensino-aprendizagem (Skliar, 2006).

A última questão da pesquisa, questão 7 , realizada aos discentes foi sobre a recomendação da IES para outros alunos que também possuem deficiência. Dos 42 alunos pesquisados, 40 informaram que recomendariam sim a IES para outros alunos com deficiência, e apenas 2 discentes informaram que não. A resposta negativa foi justificada pelo fato de os acadêmicos não terem se sentindo confortável em alguns pontos da IES, como por exemplo, na reprografia, que ainda falta ser adaptada para alunos cadeirantes no quesito altura dos computadores disponíveis para utilização. Alguns ambientes de usos comuns, como laboratórios e banheiros foram bem elogiados por terem as adaptações necessárias.

Sabe-se que para o processo de inclusão são necessários investimentos em materiais pedagógicos, qualificação de professores, infraestrutura adequada para ingresso, acesso e permanência e estar atento a qualquer forma discriminatória, pois o aluno deve estar acolhido em todas as dependências das instituições e também na metodologia de ensino utilizada pelos professores (Moreira, 2005).

Com relação aos resultados advindos dos questionários aplicados para os professores e demais colaboradores que possuem contato com os discentes portadores de necessidades especiais, obteve-se a primeira questão, que foi a respeito do suporte necessário para lidar com o aluno especial, ou seja, se o colaborador passou por algum tipo de treinamento ou capacitação adequada para lidar com estes alunos. Dos 87 colaboradores entrevistados, 76 afirmaram que tiveram o suporte necessário e 11 informaram que não tiveram este suporte, tendo passado por várias dificuldades com certos tipos de necessidades educacionais diferenciadas.

Existem inúmeras barreiras de acessibilidade que permeiam a pessoa com deficiência. Vale ressaltar que mesmo o ambiente educacional tendo um público frequentador de pessoas com deficiência, ainda existem melhorias a serem adotadas (Cruz, 2020). No que se refere ao preparo dos colaboradores envolvidos, seria de suma importância que a IES, por meio das reuniões pedagógicas, instruísse estes colaboradores de algumas práticas de inclusão para as principais deficiências encontradas na própria IES.

A questão número 2 é referente a indicação do serviço oferecido pelo NAEE, se no caso dos professores eles indicam para seus alunos procurarem o setor, e se no caso dos funcionários se estes também recomendam o serviço para seus amigos. Dos 87 colaboradores pesquisados, todos afirmaram que sim, recomendam o serviço oferecido pelo NAEE para seus alunos e amigos, pois acreditam em uma parceria entre sala de aula, infraestrutura da instituição e o serviço ofertado pelo NAEE.

A questão número 3 abrangeu as reuniões pedagógicas que são feitas semestralmente pela IES, onde são apresentados os setores para os novos docentes e funcionários recém-contratados. Neste tipo de reunião são feitas orientações acerca dos trabalhos realizados pelos setores. Dos 87 colaboradores pesquisados, 80 informaram que cumprem as orientações informadas pela equipe do NAEE e pelas reuniões pedagógicas. Os demais informaram que ainda não tiveram a oportunidade de colocar em prática alguns pontos trabalhados nas reuniões.

$\mathrm{Na}$ questão de número 4 foi questionado se o colaborador se sente preparado para lidar com as necessidades 
educacionais especializadas encontradas nos discentes matriculados da IES. Dos 87 colaboradores, 62 informaram que sim e 25 informaram que não se sentem capacitados para lidar com as diferenças encontradas na IES. A maior queixa foi a diversidade encontrada, já que a mesma recebe alunos dos mais variados nichos, sendo um desses nichos as deficiências cognitivas, que acabam exigindo um pouco mais dos docentes.

Fávero (2007) aponta que existem situações em que é necessário considerar os meios excludentes e oferecer tratamentos diferenciados a determinadas pessoas, com o intuito de promover a igualdade de oportunidades, uma vez que a educação evidencia o paradoxo inclusão/exclusão, no qual democratizam o acesso, mas continua a segregar grupos considerados fora dos padrões idealizados.

A questão de número 5, última questão aplicada aos colaboradores, foi a respeito da indicação da IES para outras pessoas que também possuem algum tipo de deficiência. Dos 87 colaboradores pesquisados, 86 afirmaram que indicariam sim a IES para outras pessoas que possuem algum tipo de deficiência. Apenas uma negou a resposta, por conta de a instituição contar apenas com 1 intérprete de libras, e esta pessoa informou que pelo tamanho da instituição, a mesma deveria contar com mais profissionais desta área.

Portanto, é possível afirmar que, de sobremaneira, a inclusão é entendida como um princípio filosófico, devendo orientar ações cotidianas e considerar que todos nascem livres e iguais em dignidade e direitos, além de terem direito à educação, conforme o que está estabelecido na Declaração Universal dos Direitos Humanos (ONU, 1948). Essa declaração por si só, deveria bastar para que as pessoas com necessidades educacionais e físicas tivessem o direito à educação e ao convívio em ambientes comuns de vida social (Oliveira, 2006).

\section{Conclusão}

A IES utilizada neste relato fornece subsídios necessários para viabilizar o processo de inclusão. Os professores e colaboradores se sentem preparados e dispostos a receberem alunos especiais. Foi observado que os cursos que recebem acadêmicos com necessidades educacionais especiais estão sempre buscando meios de inserir esses alunos da melhor forma possível. Quanto aos alunos, o principal obstáculo enfrentado por eles é a falta de conhecimento e conscientização da população acadêmica com relação às necessidades educacionais especiais. Este é um fator que precisa ser mais bem trabalhado e divulgado na IES, possibilitando a todos os docentes e discentes, o entendimento e o auxílio necessário para a efe tivação do processo inclusivo.

Diante do exposto, conclui-se que garantir o acesso aos alunos com necessidades educacionais especiais envolve não só manter o aluno na IES, mas sim garantir uma permanência de qualidade, onde o direito de cada um seja mantido com igualdade. Pode-se afirmar que os alunos que possuem algum tipo de deficiência estão satisfeitos com o serviço oferecido pela IES e pelo NAEE, pois os mesmos informaram pontos positivos e que indicariam a IES e os serviços prestados para outras pessoas com deficiências. Em relação aos professores e colaboradores, mais da metade informou estar satisfeito com a sua condição em relação aos alunos com deficiências e relataram estar sempre passando por treinamentos adequados e se tornando capacitados para lidarem com as diversidades encontradas na IES.

Diante deste cenário, é evidente a importância do professor como facilitador no processo de ensino-aprendizagem e, como perspectivas de trabalhos futuros sugere-se mapear as metodologias dos docentes em sala de aula, visto que, os alunos não são todos iguais, a diversidade está presente também no ambiente educacional. Para isso, seria fundamental entender como funciona a interação direta entre os alunos com deficiência e seus professores, para que a educação inclusiva no ensino superior do Brasil seja justa e acessível a todos. 


\section{Referências}

Brasil. (1996). Lei $n 9.394$ de 20 de dezembro de 1996: Estabelece as diretrizes e bases da educação nacional. http://www.planalto.gov.br/ccivil_03/leis/19394.htm.

Brasil. (1988). Constituição Federal. Brasília.

Chahini, T. H, C. (2010). Atitudes sociais e opiniões de professores e alunos da universidade federal do Maranhão em relação à inclusão de alunos com deficiência na educação superior, 131f. Tese (Doutorado em Educação) - Universidade Estadual Paulista, Faculdade de Filosofia e Ciências, Marília.

Cheer, J., et al. (2003). Access barriers for persons with disabilities: the consumer's perspective. J Disabil Pol Studies. 13(4):221-31. DOI: $10.1177 / 104420730301300404$.

Cruz, V. V., et al. (2020). Barreiras de acessibilidade para pessoas com deficiência ou mobilidade reduzida: revisão integrativa. Research, Society and Development, 9(4), e168943053. https://doi.org/10.33448/rsd-v9i4.3053.

Dussilek, C. A., \& Moreira, J. C. C. (2017). Inclusão no ensino superior: uma revisão sistemática das condições apresentadas aos estudantes com deficiência. Research, Society and Development, 6(4), 317-341. https://doi.org/10.17648/rsd-v6i4.124.

Fávero, E. A. G. (2007). Direitos das Pessoas com Deficiência: Garantia de Igualdade na Diversidade - Rio de Janeiro: WVA Ed.

Guerreiro, E. M. B. R. (2012). A acessibilidade e a educação: um direito constitucional como base para um direito social da pessoa com deficiência. Rev. Educ. Espec. Santa Maria, v. 25, n. 43, p. 217-232.

Kroll, T., et al. (2006). Barriers and strategies affecting the utilization of primary preventive services for people with physical disabilities: a qualitative inquiry. Health Soc Care Community. 14(4):284-93. DOI:10.1111/j.1365- 2524.2006.00613.x.

Leite, F. P. A. (2007). O município acessível a pessoa portadora de deficiência: o direito à eliminação das barreiras arquitetônicas. São Paulo: RCS Editora.

Malheiro, S. J. (2018). Acessibilidade na Educação a Distância. Dicionário Crítico de Educação e Tecnologias e de educação a Distância. Daniel Mill (org) Campinas: Papirus Editora.

Moreira, L. C., et al. (2011). Ingresso e permanência na Universidade: alunos com deficiências em foco. Educar em Revista, Curitiba: Editora UFPR, Brasil, n. 41, p. 125-143.

Nagai, R., et al. (2007). Conhecimentos e práticas de adolescentes na prevenção de acidentes de trabalho: estudo qualitativo. Rev Saúde Pública. 41(3):404-11. DOI: $10.1590 /$ S0034- 89102007000300012.

Nicholl, A. R. J. (2001). O Ambiente que Promove a Inclusão: Conceitos de Acessibilidade e Usabilidade. Revista Assentamentos Humanos, Marília, v3, n. 2, p 49- 60 .

Oliveira, A. A. S. (2006). Inclusão no Brasil: políticas públicas para o educando com necessidades educacionais especiais. São José dos Campos: Editora Pulso.

Organização das Nações Unidas (ONU). 2006. Declaração dos direitos das pessoas deficientes.

Quines, S., et al. (1985). The use of focus groups with the disabled elderly. Qual Health Res. 5(4):454-62. DOI:10.1177/104973239500500406.

Rosseto, E. (2009). Recuperação histórica das politicas de inclusão no ensino superior. Campinas: Faculdade de Educação - UNICAMP, 2009. Disponível em: www.histedbr.fae.unicamp.br/acer_histedbr/seminario/.../WrKNHCJb.doc.

Silva, K. C. (2016). Conditions of accessibility at the university: the point of view of students with disabilities. 149f. Dissertation (MA in Education) Universidade Estadual Paulista, Faculdade de Filosofia e Ciências, Marília.

Simionato, M. A. W. (2011). O deficiente no Ensino Superior: uma reflexão. Maringá: Eduem, p. 299-313.

Skliar, C. (2006). A inclusão que é “nossa” e a diferença que é do "outro”. Inclusão e Educação: doze olhares sobre a educação inclusiva. São Paulo: Summus, p.16-34.

Stroparo, E. M., et al. (2016). O papel da biblioteca universitária na inclusão de alunos com deficiência superior. Revista do Centro da Educação, vol. 41, núm 1, p 209-222. 2016. 